\title{
Offload zones to mitigate emergency medical services (EMS) offload delay in the emergency department: a process map and hazard analysis
}

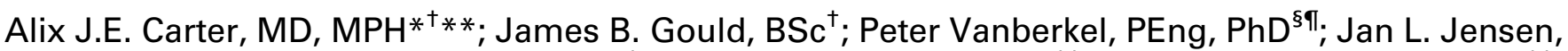 \\ ACP, MAHSR***; Jolene Cook, MD ${ }^{\dagger}$; Steven Carrigan, MPA ${ }^{+\dagger}$; Mark R. Wheatley, ACP ${ }^{+t}$; \\ Andrew $\mathrm{H}$. Travers, MSc, MD* ${ }^{* \ddagger}$
}

\section{ABSTRACT}

Introduction: Offload delay is a prolonged interval between ambulance arrival in the emergency department (ED) and transfer of patient care, typically occurring when EDs are crowded. The offload zone (OZ), which manages ambulance patients waiting for an ED bed, has been implemented to mitigate the impact of ED crowding on ambulance availability. Little is known about the safety or efficiency. The study objectives were to process map the $\mathrm{OZ}$ and conduct a hazard analysis to identify steps that could compromise patient safety or process efficiency.

Methods: A Health Care Failure Mode and Effect Analysis was conducted. Failure modes (FM) were identified. For each FM, a probability to occur and severity of impact on patient safety and process efficiency was determined, and a hazard score (probability $X$ severity) was calculated. For any hazard score considered high risk, root causes were identified, and mitigations were sought.

Results: The OZ consists of six major processes: 1) patient transported by ambulance, 2) arrival to the ED, 3) transfer of patient care, 4) patient assessment in $O Z, 5)$ patient care in $\mathrm{OZ}$, and 6) patient transfer out of $\mathrm{OZ} ; 78 \mathrm{FM}$ were identified, of which 28 (35.9\%) were deemed high risk and classified as impact on patient safety $(n=7 / 28,25.0 \%)$, process efficiency ( $n=10 / 28,35.7 \%)$, or both $(n=11 / 28,39.3 \%)$. Seventeen mitigations were suggested.

Conclusion: This process map and hazard analysis is a first step in understanding the safety and efficiency of the OZ. The results from this study will inform current policy and practice, and future work to reduce offload delay.

\section{RÉSUMÉ}

Introduction: Le retard de déchargement des ambulances se définit comme la prolongation de l'intervalle entre l'arrivée des ambulances au service des urgences (SU) et le transfert de la responsabilité des soins donnés aux patients; le problème se produit généralement en période d'encombrement des SU. Des zones de déchargement (ZD) des ambulances, là où les patients arrivés en ambulance sont traités dans l'attente d'un lit au SU, ont donc été ménagées afin d'atténuer l'effet de l'encombrement des SU sur la disponibilité des ambulances. Toutefois, on connaît peu de choses sur la sécurité ou l'efficacité de ces zones. L'étude visait à schématiser le processus du concept des ZD et à mener une analyse des dangers afin que soient décelés les maillons faibles de la chaîne, susceptibles de diminuer la sécurité des patients ou l'efficacité du processus.

Méthode: Les auteurs ont mené une analyse des modes de défaillance (MD) des soins de santé et de leurs effets. Ont été décelés différents modes de défaillance (MD), et les probabilités qu'ils se produisent ainsi que le degré de gravité de leur incidence sur les patients et sur l'efficacité du processus ont été déterminés pour chacun d'eux, après quoi les auteurs ont calculé une cote de danger (multiplication des probabilités par la gravité). Chaque fois qu'une cote de danger était considérée comme "élevée ", il y a eu recherche des causes premières et de moyens d'atténuation.

Résultats: Le concept des ZD se divise en 6 grandes étapes: 1) le transport des patients en ambulance; 2) I'arrivée au SU; 3) le transfert de la responsabilité des soins donnés aux patients; 4) I'évaluation de l'état des patients dans la ZD; 5) la prestation de soins aux patients dans la ZD; 6) la sortie des patients de la ZD. Soixante-dix-huit MD ont été relevés et, sur ce nombre, $28(35,9 \%)$ ont été jugés "à risque élevé " et classés en fonction de leur incidence sur la sécurité des patients ( $n=7 / 28 ; 25,0 \%)$, sur l'efficacité du processus ( $n=10 / 28 ; 35,7 \%$ ) ou sur l'un et l'autre de ces éléments ( $n=11 / 28 ; \quad 39,3 \%$ ). Ont été suggérées 17 mesures d'atténuation.

From the *Emergency Health Services, Dartmouth, NS; Departments of †Emergency Medicine; ¥Community Health and Epidemiology; §Industrial Engineering, Dalhousie University, Halifax, NS; ףIWK Health Centre, Halifax, NS; **Division of Emergency Medical Services, Dalhousie University, Halifax, NS; and t+Emergency Health Services, Halifax, NS.

Correspondence to: Dr. Alix Carter, Dalhousie University, Department of Emergency Medicine, Division of Emergency Medical Services, Halifax Infirmary, Room 3022, 1796 Summer Street, Halifax, NS B3H 3A7; Email: alix.carter@gov.ns.ca

(C) Canadian Association of Emergency Physicians 2015 CJEM 2015;17(6):670-678

DOI 10.1017/cem.2015.15 
Conclusions: La schématisation du processus et l'analyse des dangers constituent la première étape de la compréhension de la sécurité et de l'efficacité des ZD. Les résultats de l'étude jetteront un éclairage nouveau sur la politique appliquée actuellement et sur la pratique en cours, ainsi que sur les futurs travaux visant à réduire les délais de déchargement.

Keywords: emergency medical services, emergency service, hospital crowding, process assessment (health care)

\section{INTRODUCTION}

\section{Offload delay}

The transfer of patient care from emergency medical services (EMS) paramedics to emergency department (ED) staff must balance returning ambulances to service, and an often crowded ED. Offload delay (OD) describes a delay between ambulance arrival at the ED and transfer of patient care, that is, a prolongation of the delivery portion of the turnaround or at-hospital interval. ${ }^{1,2}$ For paramedics to transfer patient care and become available for the next response, a verbal report must be given to ED staff, and the patient must be transferred off of the EMS stretcher. ${ }^{3}$

OD typically occurs when an ED reaches its maximum capacity and there are no beds in which to place a newly arrived patient. ${ }^{4-6} \mathrm{~A}$ recent study by Cooney et al. showed a positive correlation between median OD times and National Emergency Department Overcrowding Scale scores ${ }^{3}$ - a tool for measuring and tracking the degree of hospital crowding.

OD impacts both individual patients and the EMS system. Typically, a patient experiencing OD is not seen by the emergency physician, and care (diagnostics and treatment) is limited to the scope and equipment of the paramedic crew. This may or may not allow for limited quantities of medication for pain, nausea, and so on, depending on the level of certification of the crew. For example, an advanced care paramedic drug pouch would be stocked with $10 \mathrm{mg}$ (maybe up to $20 \mathrm{mg}$ ) of morphine as the only narcotic, and a primary care paramedic would have no narcotics. Diagnostics would not usually begin. This places the patient at a risk for delays in patient care, poor pain control, delayed time to antibiotics, increased morbidity and potentially increased mortality, as we have seen for those in the waiting room. ${ }^{7,8}$ In some EDs, a physician will begin assessment and workup in the offload hallway, but the patient may not move to an ED or inpatient bed, opening them up to the risks associated with prolonged boarding in the ED. ${ }^{9,10}$ Furthermore, impacts on EMS systems could have implications for the overall health care system; the more time that ambulance crews spend delayed in the hospital, the less time that they are available for emergency response in the community. ${ }^{11}$ This could result in a consumption of resources and need for additional EMS staffing to compensate. Preliminary evaluation work out of Alberta suggests a significant improvement of EMS efficiency and costeffectiveness if OD is reduced. ${ }^{12} \mathrm{OD}$ is worsening; the 90th percentile of delivery intervals in Nova Scotia had been increased over 5 years from 24 minutes, 37 seconds in 2002 to 109 minutes, 2 seconds in $2007 .{ }^{13}$ By 2010, two of Nova Scotia's most affected urban EDs-The Queen Elizabeth II Health Science Centre and Dartmouth General Hospital-reported OD times of 114 minutes and 142 minutes, respectively, 90\% of the time. ${ }^{14}$ Recently, EMS systems in Nova Scotia have estimated their OD times at 2,900 hours annually, which equates to approximately $\$ 754,000$ at the average paramedic salary.

\section{Offload zone concept}

The Queen Elizabeth II Health Science Centre and Dartmouth General Hospital EDs, in collaboration with Emergency Health Services (EHS), have attempted to reduce offload time by implementing offload zones (OZ). ${ }^{14}$ The $\mathrm{OZ}$ functions as follows: if there are no available ED beds when paramedics arrive with a patient, the patient is placed in the OZ, in the care of a dedicated nurse and paramedic. The ambulance (and paramedic crew) then clears the ED and is available for another emergency response. The $\mathrm{OZ}$ with these two staff can serve as a transition zone for multiple patients at the same time, eliminating the need for one ambulance (and paramedic crew) to wait with each patient. Patient eligibility for the OZ depends on the patient's Canadian Triage and Acuity Scale (CTAS). When the majority of patients are low acuity, then the staff may accept up to six patients; however, if some of the patients in the $\mathrm{OZ}$ are of higher acuity and require 
more care, then fewer patients may be accepted at the discretion of the OZ staff. It is important to note that the $\mathrm{OZ}$ beds do not add to the overall ED bed capacity. By protocol, the $\mathrm{OZ}$ does not take walk-in patients; it is dedicated to ambulance patients only. Diagnostic workup and definitive treatment are not intended to begin in the $\mathrm{OZ}$, and staffing does not contribute to overall ED capacity; the two staff members are dedicated to the $\mathrm{OZ}$ during their shifts (i.e., do not work in other areas of the ED or respond to ambulance calls). The $\mathrm{OZ}$ is simply intended to allow one twoperson crew to wait with up to six ambulance patients, instead of six ambulance crews waiting. Similar concepts to the $\mathrm{OZ}$ have been implemented in other institutions. The Ministry of Health and Long-Term Care in Ontario has funded a dedicated project involving nurses who monitor offload patients similar to those in the OZ. ${ }^{15}$ Another example is a dedicated ambulance receiving nurse who has been linked to improved length of stay, time to treatment, and as much as a $15 \%$ decrease in OD. ${ }^{16}$

\section{Research objective}

The objectives of this study were to 1) develop a process map that accurately portrays the real life functioning of the $\mathrm{OZ}$ and to 2) conduct a hazard analysis to evaluate the $\mathrm{OZ}$ process. The aim is to quantify and understand the process, and to identify any failures that could adversely affect patient safety or process efficiency and to recommend actions or changes that would prospectively avoid these failures.

\section{METHODS}

\section{Process map and Health Care Failure Mode and Effect Analysis}

This study followed the Health Care Failure Mode and Effect Analysis (HFMEA) method to develop a process map of the real life functioning of the $\mathrm{OZ}$ and to conduct a hazard analysis in order to identify any risks to patient safety or process efficiency. Failure Mode and Effect Analysis (FMEA) is a method often used in engineering to calculate the vulnerabilities of various systems and equipment. Building on this, HFMEA was developed to specifically analyse health care processes. HFMEA is meant to be proactive, in contrast to reporting systems that typically analyse adverse events after they have occurred. ${ }^{17}$ The HFMEA process has been used to map and study other complex processes in EMS, including paramedic-administered rapid sequence intubation and myocardial infarction management with prehospital fibrinolytics. ${ }^{18,19}$ This study was given a waiver of research ethics review by the Capital District Health Authority Research Ethics Board.

\section{Setting}

EMS in Nova Scotia, including ground and air ambulance, dispatch, and first response, are delivered under a single contractor model. The system serves a catchment area of 55,000 square kilometres and a population of nearly 1,000,000. The province contains a mix of urban, suburban, and rural regions. In 2012, the emergency 911 call volume was approximately 132,000. Approximately 13,000 emergency calls were transported to the two EDs during this study. A staffing mix of primary, intermediate, and advanced care paramedics work in the ground ambulance system. ${ }^{19}$

The two EDs that employ the OZ (Queen Elizabeth II Health Science Centre and Dartmouth General Hospital) are both located in the capital region (Halifax) of Nova Scotia and saw approximately 168 and 102 patient visits per day, respectively, during this time frame. ${ }^{14}$ Both are teaching hospitals, and the Queen Elizabeth II Health Science Centre is the tertiary care and trauma centre for the province. The $\mathrm{OZ}$ is designed to operate from hours of 1000 to 2200 for 7 days per week and is staffed by one EHS paramedic and one ED registered nurse $(\mathrm{RN})$, dedicated to the care of the patients in the $\mathrm{OZ}$ only.

\section{Process map development}

An initial process map was drafted by direct observation and from the written protocol, by one team member. Each staff member of the $\mathrm{OZ}$ was contacted and provided with templates allowing them to map any conceivable step that could occur as patients flow through the OZ. Paramedics in the ground ambulance system were invited by email to participate in the same manner. The submitted maps were then used to refine the draft process map. OZ staff members were invited to participate voluntarily in focus groups, in which further refinements were made. The final map was independently validated by an assistant not directly involved with the process mapping. 


\section{Hazard analysis}

During the focus groups, which consisted of a combination of OZ staff, ground EMS crews, one ED physician, one process engineer, and one $\mathrm{OZ}$ researcher, participants identified failure modes (FM), defined as ways in which each step may fail to provide its anticipated result, by group consensus. ${ }^{13}$ Each FM was categorized as having an effect either on patient safety, on process, or both. Subsequently, participants determined the probability of the FM occurring (Table 1) and the severity (Table 2 ) of hazard by determining the effect on patient safety and the effect on process, if it did occur. ${ }^{17}$ By discussion and consensus, hazard mode scores were calculated (i.e., the product of probability and severity) and the hazard matrix populated (Table 3 ). Any hazard mode with a score greater than or equal to 8 for either effect on patient safety or process was considered a high risk, and a root cause analysis was completed. A second hazard mode score was calculated for each root cause. Again, any score greater than or equal to 8 for either effect on patient safety or process was

\begin{tabular}{|c|c|c|}
\hline $\begin{array}{l}\text { Probability } \\
\text { score }\end{array}$ & & Definition \\
\hline 4 & Frequent & $\begin{array}{l}\text { Likely to occur immediately or within a } \\
\text { short period ( } 1 \text { per week) }\end{array}$ \\
\hline 3 & Occasional & Probably will occur (1 per month) \\
\hline 2 & Uncommon & Possible to occur (1 per year) \\
\hline 1 & Remote & Unlikely to occur (1 per 2-3 years) \\
\hline
\end{tabular}

considered a high-risk cause. Suggestions for mitigation were made for the high-risk causes that did not have an already existing control measure.

\section{RESULTS}

The process map (Figure 1) consists of six major processes: 1) patient transported by ambulance, 2) arrival in $\mathrm{ED}, 3)$ transfer of patient care, 4) patient assessment in $\mathrm{OZ}, 5$ ) patient care in $\mathrm{OZ}$, and 6) patient transfer out of $\mathrm{OZ}$ to ED. There were 110 steps within these major processes (Table 4). The major processes with the most steps were 3) transfer of patient care ( $n=42$ steps, $38.2 \%)$ and 4$)$ patient assessment in OZ ( $n=27,24.5 \%)$.

There were 78 FMs identified, of which 28 (35.9\%) were deemed high risk and further classified as the following: effect on patient safety $(n=7 / 28,25.0 \%)$, effect on process ( $n=10 / 28,35.7 \%)$, or both $(n=11 / 28$, $39.3 \%$ ). There were 57 causes for high-risk FMs identified, of which 51 (89.5\%) then scored as high risk

Table 3. Hazard mode score matrix

\begin{tabular}{|c|c|c|c|c|}
\hline \multirow[b]{2}{*}{ Probability } & \multicolumn{4}{|c|}{ Severity } \\
\hline & $\begin{array}{c}\text { Catastrophic } \\
\text { (4) }\end{array}$ & $\begin{array}{l}\text { Major } \\
\text { (3) }\end{array}$ & $\begin{array}{c}\text { Moderate } \\
\text { (2) }\end{array}$ & $\begin{array}{l}\text { Minor } \\
\text { (1) }\end{array}$ \\
\hline Frequent (4) & 16 & 12 & 8 & 4 \\
\hline Occasional (3) & 12 & 9 & 6 & 3 \\
\hline Uncommon (2) & 8 & 6 & 4 & 2 \\
\hline Remote (1) & 4 & 3 & 2 & 1 \\
\hline
\end{tabular}

Table 2. Severity rating scale

\begin{tabular}{|c|c|c|c|}
\hline \multirow{2}{*}{$\begin{array}{l}\text { Severity } \\
\text { score }\end{array}$} & \multirow[b]{2}{*}{ Patient outcome } & \multicolumn{2}{|c|}{ Definition } \\
\hline & & Effect on patient & Effect on process \\
\hline 4 & Catastrophic event & $\begin{array}{l}\text { Severe harm. Could cause death or severe injury; } \\
\text { patient or family would definitely notice } \\
\text { appropriate care was not delivered }\end{array}$ & $\begin{array}{l}\text { Offload process severely disrupted. Patients } \\
\text { backlog several hours }\end{array}$ \\
\hline 3 & Major event & $\begin{array}{l}\text { Moderate harm. Could cause injury or increase } \\
\text { level of care required; event definitely noticeable } \\
\text { to the patient }\end{array}$ & $\begin{array}{l}\text { Immediate process causes other patients/ } \\
\text { processes to experience delay }\end{array}$ \\
\hline 2 & Moderate event & $\begin{array}{l}\text { Mild harm. Increased level of care required that } \\
\text { would have been expected; event may be } \\
\text { noticeable to patient }\end{array}$ & $\begin{array}{l}\text { Immediate process takes } 2-3 \text { times as long. Other } \\
\text { patients/processes do not experience delay }\end{array}$ \\
\hline 1 & Minor event & $\begin{array}{l}\text { No harm. No injury, would not be noticeable to } \\
\text { patient, would not affect delivery of care }\end{array}$ & $\begin{array}{l}\text { Immediate process Takes slightly longer than usual. } \\
\text { Not noticeable }\end{array}$ \\
\hline
\end{tabular}




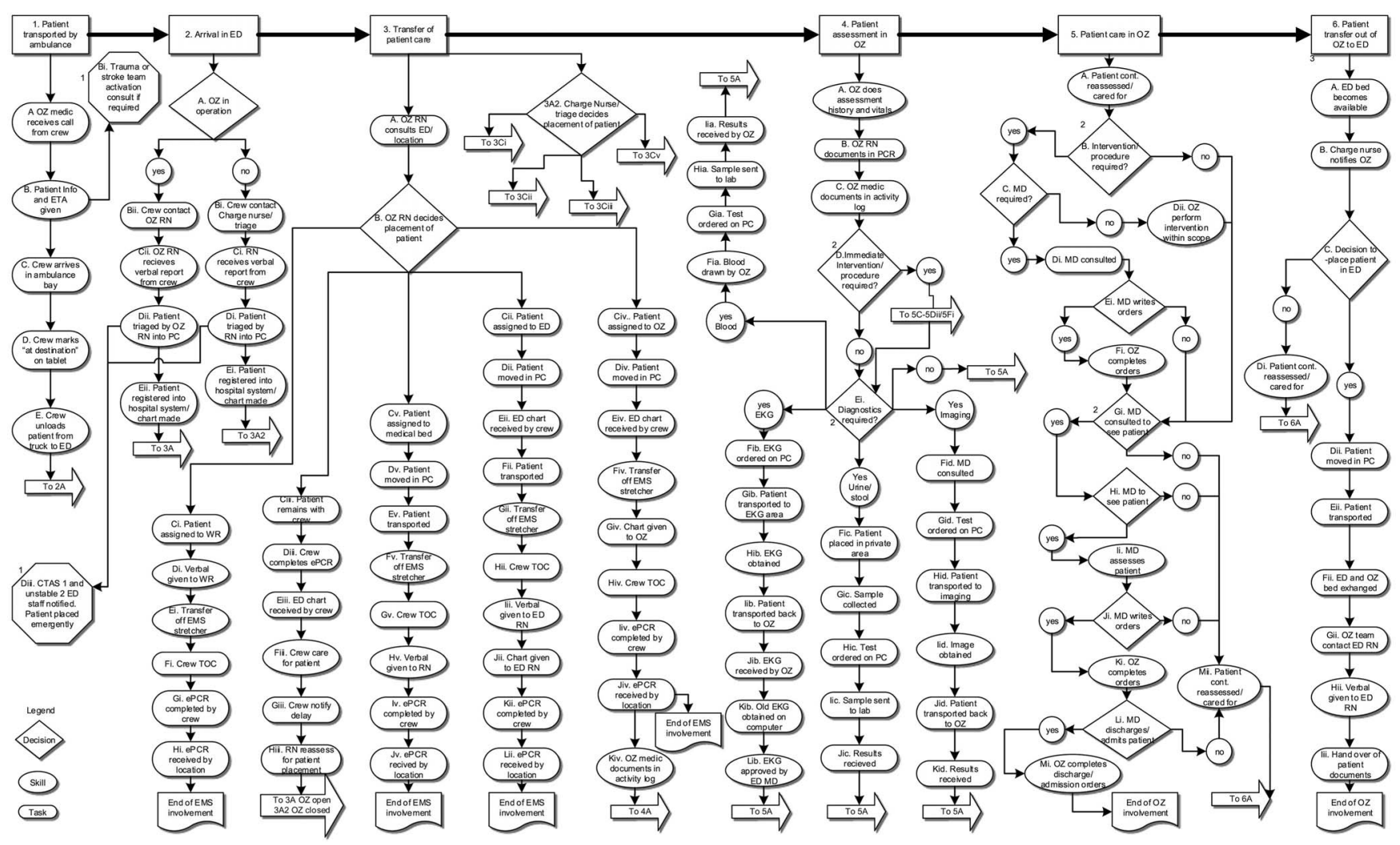

Figure 1. Process map. $\mathrm{OZ}=$ offload zone; $\mathrm{ETA}=$ estimated time of arrival; $\mathrm{ED}=$ emergency department; $\mathrm{CTAS}=\mathrm{Canadian}$ Triage and Acuity Scale; $\mathrm{RN}=$ registered nurse; $\mathrm{WR}=$ waiting room; $E M S=$ emergency medical services; TOC $=$ transfer of care; ePCR = electronic patient care report; EKG = electrocardiogram; $\mathrm{MD}=$ medical doctor.

*1. Considered tasks; 2 . Can happen at any point as soon as patient is in OZ; 3 . Can happen at any time in process.

\begin{tabular}{|c|c|c|c|c|c|c|c|}
\hline \multirow[b]{2}{*}{ Item } & \multicolumn{7}{|c|}{ Number } \\
\hline & Total & $\begin{array}{l}\text { (1) } \\
\text { Patient transported } \\
\text { by ambulance }\end{array}$ & $\begin{array}{l}\text { (2) } \\
\text { Arrival in } \\
\text { ED }\end{array}$ & $\begin{array}{c}\text { (3) } \\
\text { Transfer of } \\
\text { patient Care }\end{array}$ & $\begin{array}{c}\text { (4) } \\
\text { Patient assessment } \\
\text { in } \mathrm{OZ}\end{array}$ & $\begin{array}{c}\text { (5) } \\
\text { Patient care } \\
\text { in OZ }\end{array}$ & $\begin{array}{c}\text { (6) } \\
\text { Patient transfer } \\
\text { out of OZ to ED }\end{array}$ \\
\hline Major processes & 6 & & & & & & \\
\hline Steps (\% of total steps) & 110 & $6(5.5 \%)$ & $10(9.1 \%)$ & $42(38.2 \%)$ & $27(24.5 \%)$ & $15(13.6 \%)$ & $10(9.1 \%)$ \\
\hline Decisions (\% of steps) & $13(11.8 \%)$ & $0(0.0 \%)$ & $1(10.0 \%)$ & $2(4.8 \%)$ & $2(7.4 \%)$ & $7(46.7 \%)$ & $1(10.0 \%)$ \\
\hline Skills (\% of steps) & $29(26.4 \%)$ & $2(33.3 \%)$ & $4(40.0 \%)$ & $9(21.4 \%)$ & $5(18.5 \%)$ & $7(46.7 \%)$ & $2(20.0 \%)$ \\
\hline Tasks (\% of steps) & $68(61.8 \%)$ & $4(66.7 \%)$ & $5(50.0 \%)$ & $31(73.8 \%)$ & $20(74.1 \%)$ & $1(6.7 \%)$ & $7(70.0 \%)$ \\
\hline
\end{tabular}

and were classified as effect on patient safety $(n=13 / 51$, $25.5 \%)$, effect on process $(n=19 / 51,37.3 \%)$, or both $(n=19 / 51,37.3 \%)$. The high-risk cause with the highest hazard score with regard to effect on patient safety was the following: Patient not properly assessed/ cared for because of lack of proper equipment (hazard score $=16$ ), which could occur at steps 4A, 5A, 5Mii, 6Di(b)1 (see Figure 1 and Table 5). The high-risk cause with the highest hazard score effect on process was the following: patient not placed in ED from OZ because patient already receiving care in $O Z$ (hazard score $=16$ ), which appeared at step(s) 6C(a)5 (see Figure 1 and Table 5).

Of the 51 high-risk causes, there were 14 with existing control measures and 37 without. There were 17 mitigations (Table 5) suggested for those high-risk causes with no control measure. 
Table 5. Suggestions for action (for those high-risk FM with no control measure)

Suggestion for action

1. Hire additional OZ RN

2. Accommodations (e.g., computer and stool) in EMS corridor for clerk to sit and register patients in hallway

3. Monthly memo to all paramedic staff on TOC protocols

4. Popup reminder on ambulance crew tablet or equivalent to TOC

5. Place the number to $\mathrm{OZ}$ fax machine on ambulance crew tablets

6. Staggered ED RN shift changes

7. OZ RN goes to ED bed with OZ patient if no ambulances to triage

8. Get computer login for OZ medic

9. New chart receiving protocol for ambulance crews - transport patient to room as soon as they are assigned without waiting for chart. OZRN must move chart in PC and clerk will find patient in room based on PC entry.

10. Hire patient attendant or health care assistant for OZ who can also work ED if they are not busy

11. Further investigation
High-risk failure mode and cause*

A) 2A(a)1: OZ closed when supposed to be open because unable to staff RN that day

B) 2A(a)2: OZ closed when supposed to be open as it closed early

A) 2Eii, Ei(a)2: Delay in registration because clerk not in corridor

A) 3Fi, Gv, Hii, Hiv, Giii (a)1: Delay in notification because out-oftown crew unaware of policy

A) 3Fi, Gv, Hii, Hiv, Giii (a)2: Delay in notification because crew forgot

A) $3 \mathrm{Hi}, \mathrm{Jv}$, Lii, Jiv (a)2: ePCR not received or delayed in receiving because it was sent to fax machine that $\mathrm{OZ}$ doesn't have ease of access

A) 3Cii (a)1: Patient not placed in ED because of ED RN shift change

B) 6C(a)1: Patient not placed in ED from OZ because of ED RN shift change

A) 3Cii(a)3: Patient not placed in ED because ED RN tied up with other patients in ED

B) 6C(a)3: Patient not placed in ED from OZ because ED RN tied up with other patients in ED

A) 3 Div, Dii, Dv (a)1: Patient not moved on PC because RN not present to move them

B) 4Gia, Fib, Hic, Gid.(a)1: Not able to order a test because RN not present to order on computer

C) 4.Kib (a)1: Delay in retrieval of old EKG on PC because RN not present to log in to computer

A) 3Eii, Eiv, Eiii(a)1: Delay in receiving chart because crew is waiting for clerk to bring them chart

A) 3Hiii.(a)1: Patient not reassessed for placement because OZ team busy with other patients

B) 4A, 5A, 5Mii, 6Di.(a)1: Delay in assessment/patient care because $\mathrm{OZ}$ team busy with other patients

C) 4Gib, lib.(a)1: Delay in transporting patient to/from EKG because OZ team busy with other patients

D) 4 Fic (a)1: Delay in getting patient in private area because $\mathrm{OZ}$ team busy with other patients

E) $4 \mathrm{Hid}(\mathrm{a}) 1$ : Delay in transport of patient to imaging because $\mathrm{OZ}$ team unable to prep patient because they are busy with other patients

F) 5Fi(a)1: Delay in completing order because OZ team busy with other patients

G) 5Ki(a)1: Delay in completing order because OZ team busy with other patients

H) 5Mi(b)1: Delay in completing discharge order because OZ team busy with other patients

A) 3Hiii.(a)3: Patient not reassessed for placement because patient already receiving care in corridor with crew

B) 6C(a)5: Patient not placed in ED from OZ because patient already receiving care in $\mathrm{OZ}$

C) 6C(a)6: Patient not placed in ED from OZ because ED waiting for patient to receive some level of care from $\mathrm{OZ}$ 


\begin{tabular}{|c|c|}
\hline Suggestion for action & High-risk failure mode and cause* \\
\hline 12. Add portable device for measuring vital signs & $\begin{array}{l}\text { A) } 4 \mathrm{~A}, 5 \mathrm{~A}, 5 \mathrm{Mii}, 6 \mathrm{Di} \text {.(a)2: Delay in assessment/patient care because } \\
\text { limited equipment already in use } \\
\text { B) } 4 \mathrm{~A}, 5 \mathrm{~A}, 5 \mathrm{Mii}, 6 \mathrm{Di}(\mathrm{b}) 2 \text { : Patient not properly assessed/cared for } \\
\text { because lack of sufficient number of equipment }\end{array}$ \\
\hline $\begin{array}{l}\text { 13. Add private area to } \mathrm{OZ} \text { - either using a curtain in the hallway or } \\
\text { room }\end{array}$ & $\begin{array}{l}\text { A) } 4 \mathrm{~A}, 5 \mathrm{~A}, 5 \mathrm{Mii}, 6 \mathrm{Di} \text {.(a)3: Delay in assessment/patient care because } \\
\text { lack of privacy } \\
\text { B) } 4 \mathrm{~A}, 5 \mathrm{~A}, 5 \mathrm{Mii}, 6 \mathrm{Di}(\mathrm{b}) 3 \text { : Patient not properly assessed/cared for } \\
\text { because lack of privacy } \\
\text { C) } 4 \mathrm{Hid}(\mathrm{a}) 2 \text { : Delay in patient transport to imaging because no } \\
\text { privacy available for patient prep } \\
\text { D) } 5 \mathrm{Hi}(\mathrm{a}) 1 \text { : } \mathrm{MD} \text { decides not to see patient who needs to see MD } \\
\text { because of privacy issues in the hallway }\end{array}$ \\
\hline $\begin{array}{l}\text { 14. Add device with cardiac monitoring and defibrillation } \\
\text { technology }\end{array}$ & $\begin{array}{l}\text { A) } 4 \mathrm{~A}, 5 \mathrm{~A}, 5 \mathrm{Mii}, 6 \mathrm{Di}(\mathrm{b}) 1 \text { : Patient not properly assessed/cared for } \\
\text { because of lack of proper equipment }\end{array}$ \\
\hline $\begin{array}{l}\text { 15. Add OZ specific chart/form for documentation of patient } \\
\text { information }\end{array}$ & $\begin{array}{l}\text { A) 4B, C (a)1: Lack of patient documentation because inappropriate } \\
\text { form available } \\
\text { B) } 4 B, C \text { (a)2: Lack of patient documentation because confusion in } \\
\text { who documents on what }\end{array}$ \\
\hline 16. Add folder outside OZ office with flag for completed EKGs & $\begin{array}{l}\text { A) 4Jib (a)1: EKG result not received because it was lost in papers } \\
\text { on OZ desk }\end{array}$ \\
\hline $\begin{array}{l}\text { 17. Expand scope of } \mathrm{OZ} \text { medic to include requirements of } \mathrm{OZ} \\
\text { patients or hire ACP or equivalent }\end{array}$ & $\begin{array}{l}\text { A) } 5 \text { Dii(a)1: Intervention that is required is not performed or delayed } \\
\text { because intervention not within scope of medic who is only } \\
\text { person available } \\
\text { B) } 5 \text { Ki(a)2: Delay in completing order because not within scope of } \\
\text { medic who is only person available }\end{array}$ \\
\hline
\end{tabular}

$\mathrm{OZ}=$ offload zone; $\mathrm{ETA}=$ estimated time of arrival; $\mathrm{ED}=$ emergency department; $\mathrm{CTAS}=$ Canadian Triage and Acuity Scale; $\mathrm{RN}=$ registered nurse; $\mathrm{WR}=$ waiting room;

$\mathrm{EMS}=$ emergency medical services; $\mathrm{TOC}=$ transfer of care; $\mathrm{ePCR}=$ electronic patient care report; $\mathrm{EKG}=$ electrocardiogram; $\mathrm{MD}=$ medical doctor; $\mathrm{ACP}=$ advanced care paramedic; *High-risk failure mode and cause $=$ major process - step - (failure mode) - cause.

\section{DISCUSSION}

As long as there has been ED crowding, EMS has been involved in mitigation strategies. Initially, ambulances were diverted away from crowded EDs. In more recent years, due to concerns of patient safety and long transport times, diversion has fallen out of favour; however, the practice of holding patients on ambulance stretchers, cared for by the transporting paramedic crew, has become more common. In some EDs, an attempt has been made through the creation of $\mathrm{OZ}$ to free up paramedics to be available for the next emergency response. This study is a foundational piece in understanding $\mathrm{OZ}$, through development of a process map that accurately portrays the real-life functioning of the $\mathrm{OZ}$ and the conduct of a hazard analysis of the $\mathrm{OZ}$.

The OZ is complex, with many steps for each major process. The most complex were 3) transfer of patient care and 4) patient assessment in OZ, with the majority of steps being tasks $(73.8 \%$, and $74.1 \%$, respectively). It is important to be aware of the high density of steps in these two major processes because they could be most vulnerable to failures. Overall, the 110 steps identified in the process map have a heavy weighting on tasks, similar to the distribution identified in another EMS process map involving paramedic-administered rapid sequence intubation: $18 \%$ decisions, $62 \%$ tasks. ${ }^{18}$ The hazard analysis revealed a number of potential failures in the most task-dense steps; $35.9 \%$ were high risk to patient safety, process efficiency, or both.

In order to alleviate potential risks to patient safety and process efficiency, 17 mitigations were suggested (Table 5) for the 37 high-risk causes that had no existing control measure. For example, a great deal of the risk to both patient safety and process efficiency was due to either the $\mathrm{OZ}$ paramedic or $\mathrm{OZ} \mathrm{RN}$ being occupied with other patients in the $\mathrm{OZ}$ or triaging other ambulance patients. It was felt that if a patient attendant or health care assistant were added, they could attend to the tasks that do not require the 
expertise of a paramedic or RN. It has been suggested that the use of health care assistants in general practice has the potential to free up other staff, including RNs, for more complex tasks, to decrease wait times, and to increase patient satisfaction. ${ }^{20}$

The high-risk cause with the largest hazard score for an effect on patient safety was the following: patient not properly assessed/cared for because of lack of proper equipment. It was determined that this was high risk to patient safety because the $\mathrm{OZ}$ does not currently have any means to monitor cardiac activity yet the $\mathrm{OZ}$ receives patients with chest pain. Furthermore, the $\mathrm{OZ}$ does not have its own device for defibrillation, which could result in patient death in the event that it was required. Studies have shown that in-hospital factors, such as lack of cardiac monitoring, can contribute to delays in recognition and management. ${ }^{21}$ In hopes to alleviate this risk, a suggestion was made (Table 5) to add a device with multifunction cardiac monitoring and defibrillation.

One unexpected finding of the process map was that the real-life functioning of the $\mathrm{OZ}$ deviated significantly from the original protocol. The original intent of the $\mathrm{OZ}$ was to monitor up to six ambulance patients at the same time in order to reduce the need for one paramedic crew to remain for each patient, therefore allowing the paramedics to return to the community. The steps in the original OZ protocol did not include providing patient care (beginning investigations, etc.) in the OZ; however, process mapping has shown that the $\mathrm{OZ}$ evolved to an area of extensive patient care. Major steps 4) patient assessment in $\mathrm{OZ}$ and 5) patient care in $\mathrm{OZ}$ consist of diagnostics, procedures, treatments, and even physician assessments. The highest hazard score for an effect on process efficiency was related to medical care in the OZ: patient not placed in ED from OZ because patient already receiving care in $O Z$. It is thought that this is due to a lack of incentive to move the patient to the ED from the OZ because the patient is already receiving diagnostics/physician assessments and would not directly benefit from being moved to the ED. In this model, the OZ simply becomes an extension of the ED. The argument in support of the current practice of extensive patient care in the $\mathrm{OZ}$ is that it may improve the timeliness and quality of care for those patients in the OZ. This, however, has the potential to create a backlog of arriving ambulance patients and could lead to a significant increase in OD, subsequently reducing the quality and timeliness of care for patients in the community awaiting an ambulance. In other words, providing care to patients in the $\mathrm{OZ}$ may improve the care of those few, at the risk of reducing the care of many. Future work will explore whether this is borne out by data and also whether it might be of benefit if the $\mathrm{OZ}$ were used for ED care under specific circumstances.

\section{LIMITATIONS}

One limitation is that the process map was derived from researcher observations and opinions of OZ staff and has not yet been cross-referenced with any EMS or hospital data. There were also some minor but consistent variations in how different staff conducted the OZ. However, the steps were validated with real-time observation across multiple days when different staff members were working, which does suggest that the map represents the general function of the OZ. A second limitation is that the hazard analysis was performed in three separate focus groups with variable attendance; it is possible that this may have affected the consistency of hazard scoring. Third, each of the $78 \mathrm{FM}$ and 28 high-risk FM that were identified applied to multiple steps in the map within different major processes. This may have reduced the perception of how many FM actually exist compared to the number of steps. Finally, not all of the hazard score definitions used in the hazard analysis were the traditional HFMEA definitions. Specifically, the traditional probability definitions were not used because the timelines were too large for the $\mathrm{OZ}$ analysis and would have resulted in too many "frequent" scores. Furthermore, the HFMEA has no severity score for process efficiency and so the definitions used were borrowed from FMEA process efficiency definitions for production processes, and refined by study group consensus.

\section{CONCLUSION}

This process map provides a framework for understanding the function of $\mathrm{OZ}$ that could be replicated in other institutions, and provides the basis for future study. The hazard analysis has identified a number of potential failures of the $\mathrm{OZ}$ that could impact patient safety or process efficiency. Several mitigations to prospectively avoid these failures were identified, which can inform current policy and practice. This study will help guide ongoing work that will aim to quantify OD times before and after implementation of the $\mathrm{OZ}$ concept. 
Acknowledgements: We thank the offload zone staff and Nova Scotia EHS paramedics who contributed to the process mapping and hazard analysis. This project was funded by the Dalhousie Faculty of Medicine, Patrick Madore Memorial summer studentship.

\section{Competing interests}

None declared.

\section{REFERENCES}

1. Spaite DW, Valenzuela TD, Meislin HW, et al. Prospective validation of a new model for evaluating emergency medical services systems by in-field observation of specific time intervals in prehospital care. Ann Emerg Med 1993;22(4): 638-45.

2. Cone DC, Davidson SJ, Nquyen Q. A time-motion study of the emergency medical services turnaround interval. Ann Emerg Med 1998;31(2):241-6.

3. Cooney DR, Wojcik S, Seth N, et al. Evaluation of ambulance offload delay at a university hospital emergency department. Int 7 Emerg Med 2013;6(1):15.

4. Olshaker JS, Rathlev NK. Emergency department overcrowding and ambulance diversion: the impact and potential solutions of extended boarding of admitted patients in the emergency department. 7 Emerg Med 2006;30(3):351-6.

5. Schafermeyer RW, Asplin BR. Hospital and emergency department crowding in the United States. Emerg Med (Fremantle) 2003;15(1):22-7.

6. Richardson LD, Asplin BR, Lowe RA. Emergency department crowding as a health policy issue: past development, future directions. Ann Emerg Med 2002;40(4):388-93.

7. Derlet RW, Richards JR, Kravitz RL. Frequent overcrowding in U.S. emergency departments. Acad Emerg Med 2001;8(2):151-5.

8. Derlet RW, Richards JR. Emergency department overcrowding in Florida, New York, and Texas. South Med 7 2002;95(8):846-9.

9. Ackroyd-Stolarz S, Read Guernsey J, Mackinnon NJ, Kovacs G. The association between a prolonged stay in the emergency department and adverse events in older patients admitted to hospital: a retrospective cohort study. BM7 Qual Saf 2011;20(7):564-9, doi:10.1136/bmjqs.2009.034926.
10. Mullins PM, Pines JM. National ED crowding and hospital quality: results from the 2013 Hospital Compare data. Am 7 Emerg Med 2014;32(6):634-9, doi:10.1016/j.ajem.2014.02.008.

11. Cooney DR, Millin MG, Carter A, et al. Ambulance diversion and emergency department offload delay: resource document for the National Association of EMS Physicians position statement. Prehosp Emerg Care 2011;15(4):555-61.

12. Macrae A, Wang D, Blanchard I, et al. UPSTREAMrelief: benefits on EMS offload delay of a provincial ED overcapacity protocol aimed at reducing ED boarding [Abstract]. CFEM 2012;14(S1):S4.

13. Karim S, Carter A, Ferguson J, et al. The evolution of offload delay over a six year period in a provincial EMS system [Abstract]. Prehosp Emerg Care 2009;13(1):91.

14. Capital District Health Authority. Quarterly performance report emergency departments and system flow. 2011. Available at: http://www.cdha.nshealth.ca/system/files/sites/343/ documents/quarterly-performance-emergency-february-2011. pdf (accessed July 2014).

15. Newell K, Hemlin A, Furlong G. Offload delay-returning paramedic unit hours to the street: the Ottawa approach. Can Paramed 2013;36(3):20-2.

16. Hendry L. The Intellegencer. $\$ \$ \$$ for ambulance offloading. 2012. Available at: http://www.intelligencer.ca/2012/08/30/for-ambulance-offloading (accessed August 2013).

17. DeRosier J, Stalhandske E, Bagian JP, Nudell T. Using Healthcare Failure Mode and Effect Analysis: The VA National Center for Patient Safety's Prospective Risk Analysis System. 7 Qual Improv 2002;27(5):248-67.

18. Blanchard I, Clayden D, Vogelaar G, et al. Adult prehospital rapid sequence intubation process map: a clinical management tool [Abstract]. Prehosp Emerg Care 2009;13(1):126.

19. Jensen J, Walker M, Denike D, et al. Paramedic myocardial infarction care with fibrinolytics: a process map and hazard analysis. Prehosp Emerg Care 2013;17(4):429-34, doi: $10.3109 / 10903127.2013 .804136$.

20. Bosley S, Dale J. Healthcare assistants in general practice: practical and conceptual issues of skill-mix change. $\mathrm{Br} \mathcal{7}$ Gen Pract 2008;58(547):118-24.

21. Chan PS, Krumholz HM, Nichol G, Nallamothu BK. American Heart Association National Registry of Cardiopulmonary Resuscitation Investigators. Delayed time to defibrillation after in-hospital cardiac arrest. $N$ Engl $7 \mathrm{Med}$ 2008;358(1):9-17. 